OPEN ACCESS

Edited by: Alex Stewart Stagnaro-Green, University of Illinois at Chicago,

United States

Reviewed by:

Bijay Vaidya,

University of Exeter, United Kingdom

Tim I. M. Korevaar,

Erasmus Medical Center, Netherlands

*Correspondence:

Fengxiu Ouyang

ouyangfengxiu@126.com;

ouyangfengxiu@xinhuamed.com.cn

Specialty section:

This article was submitted to

Thyroid Endocrinology,

a section of the journal

Frontiers in Endocrinology

Received: 09 July 2019 Accepted: 16 December 2019

Published: 10 January 2020

Citation:

Fan P, Luo Z-C, Tang N, Wang W,

Liu Z, Zhang J and Ouyang F (2020)

Advanced Maternal Age, Mode of Delivery, and Thyroid Hormone Levels

in Chinese Newborns.

Front. Endocrinol. 10:913

doi: 10.3389/fendo.2019.00913

\section{Advanced Maternal Age, Mode of Delivery, and Thyroid Hormone Levels in Chinese Newborns}

\author{
Pianpian Fan ${ }^{1}$, Zhong-Cheng Luo ${ }^{1,2}$, Ning Tang ${ }^{1}$, Weiye Wang ${ }^{1}$, Zhiwei Liu ${ }^{3}$, Jun Zhang ${ }^{1}$ \\ and Fengxiu Ouyang ${ }^{1 *}$
}

'Ministry of Education and Shanghai Key Laboratory of Children's Environmental Health, Xinhua Hospital, Shanghai Jiao Tong University School of Medicine, Shanghai, China, ${ }^{2}$ Department of Obstetrics and Gynecology, Prosserman Centre for Population Health Research, Lunenfeld-Tanenbaum Research Institute, Mount Sinai Hospital, Institute of Health Policy, Management and Evaluation, University of Toronto, Toronto, ON, Canada, ${ }^{3}$ Department of Neonatology, International Peace Maternity and Child Health Hospital, Shanghai Jiao Tong University School of Medicine, Shanghai, China

Objective: Thyroid hormones are essential for fetal growth and neurodevelopment, however, data on cord blood thyroid hormones are sparse in China where maternal age at childbearing is increasing in recent decades. We aimed to assess cord blood levels of free triiodothyronine (FT3), free thyroxine (FT4), and thyroid stimulating hormone (TSH) in full-term Chinese newborns, and examine potential related perinatal factors.

Methods: This study included 922 mother-newborn pairs from a prospective birth cohort enrolled in 2012-2013, Shanghai, China. Cord serum concentrations of FT3, FT4, TSH, and TPOAb were measured in newborns.

Results: Newborns born via cesarean section had higher cord serum FT3 (mean \pm SD: $1.90 \pm 1.16 \mathrm{pmol} / \mathrm{L})$ and lower cord serum TSH $(5.15 \pm 2.60 \mathrm{mlU} / \mathrm{L})$ than those born via vaginal delivery (FT3: $1.62 \pm 0.93 \mathrm{pmol} / \mathrm{L}$; TSH: $9.27 \pm 6.76 \mathrm{mlU} / \mathrm{L})$. In cesarean section deliveries, the concentration of cord serum FT3 was $0.15(95 \% \mathrm{Cl}:-0.03,0.33 ; p=$ $0.10)$ pmol/L lower in infants of mothers aged $30-34$ years, and $0.57(95 \% \mathrm{Cl}$ : 0.22, 0.92; $p=0.002) \mathrm{pmol} / \mathrm{L}$ lower in infants of mothers $\geq 35$ years compared to infants of mothers $<30$ years. Large-for-gestational-age (birth weight $>90$ th percentile) was associated with higher TSH $(p=0.02)$. Similar results were also found in vaginal deliveries.

Conclusions: In this Chinese term birth cohort, newborns born via cesarean section had higher cord serum FT3 and lower TSH than those born via vaginal delivery. Advanced maternal age was associated with lower fetal FT3. Further research is needed to understand whether this association may mediate the adverse impact of advanced maternal age on neurodevelopment in early life.

Keywords: maternal age, mode of delivery, perinatal factors, thyroid hormones, Chinese newborns, birth cohort

\section{INTRODUCTION}

Thyroid hormones, thyroxine (T4), and triiodothyronine (T3) are essential for fetal growth and neurodevelopment (1). From mid-gestation, fetal hypothalamus-pituitary-thyroid axis becomes gradually functional, and produces increasingly more fetal thyroid hormones including free triiodothyronine (FT3) and free thyroxine (FT4) (2). Thyroid peroxidase antibody (TPOAb) is 
thyroid autoantibody which is not functional antibody and merely reflects autoimmunity (3). Neonatal TPOAb are mainly from maternal origin (4). The positive TPOAb in cord blood has been associated with a higher risk of developing autoimmune thyroiditis in children and adolescents (5). In the context of newborn screening programs for congenital hypothyroidism $(\mathrm{CH})$, thyroid stimulating hormone (TSH) $(6,7)$, or T4 levels $(8,9)$ or both have been used $(10)$, while FT3, FT4, and TPOAb levels are not routinely measured.

Neonatal thyroid function screening measures TSH levels in either cord blood or heel prick blood at 48-72 h after births (11). The heel prick approach is somewhat compromised by the lack of consistent procedures in clinical practices, and TSH level may also be affected by the timing of blood collection and temperature $(6,12)$. Cord blood sampling is convenient and non-invasive. Some studies have provided the reference values for thyroid hormones in cord blood (13-16). Data on thyroid hormones in cord blood are sparse in China.

Cord blood TSH levels are elevated among neonates who have endured intrapartum stress including the induction of labor (17), long duration of labor (7), and vaginal delivery (7). However, inconsistent associations with neonatal thyroid hormones have been observed for maternal factors including gestational hypertension, preeclampsia, and gestational diabetes mellitus (GDM) (8, 18-20), and birth outcomes (15, 21-24). Inadequate adjustments for delivery factors may partly explain previous inconsistent results (20).

Advanced maternal age, commonly defined as $\geq 35$ years at the time of childbirth $(25,26)$, has become increasingly common over recent decades in China and many other countries, but its impacts on neonatal/cord blood thyroid hormone levels are not well-characterized. A study found that maternal age $>30$ years was associated with lower maternal serum FT3 and FT4 levels in the first and second trimesters of pregnancy (27). The rates of cesarean section (C-section) are high in China (68.7\% in Shanghai in the year 2009), in part due to frequent C-section on request (without medical indications) (48.4\%) (28). In the World Health Organization Global Survey between 2004 and 2008, Csection rate in China was $46.2 \%$, the highest among 24 study countries (29). This provides a unique opportunity to explore advanced maternal age and other perinatal factors in relation to fetal thyroid hormone levels in physiological conditions.

In this study, we sought to describe cord blood FT3, FT4, TSH, and TPOAb levels measured via chemiluminescent microparticle immunoassay in full-term neonates of Chinese mothers with normal thyroid function from a Shanghai birth cohort, and evaluate the impacts of maternal age, mode of delivery and other perinatal factors.

\section{METHODS}

\section{Study Design and Participants}

The data of this study was from the Shanghai Obesity and Allergy Cohort, a prospective birth cohort recruiting participants in two tertiary care hospitals in Shanghai, China, 2012-2013 (30). The cohort study is designed to evaluate the effects of environmental exposures and mode of delivery on childhood obesity and allergic diseases. Women with a singleton pregnancy at gestational age $\geq 28$ weeks were recruited. The study was approved by the Medical Ethics Committee of Xinhua Hospital, Shanghai Jiao Tong University School of Medicine. Written informed consent was obtained from all study participants.

Cord blood serum FT3, FT4, TSH, and TPOAb were measured. We excluded infants of mothers with syphilis $(n=7)$, artificial fertilization $(n=28)$, preterm deliveries $(n=33)$, and infants of mothers without information on thyroid function $(n=22)$. Also, infants of mothers with thyroid diseases (hyperthyroidism, $n=10$; hypothyroidism, $n=26$ ) were excluded (31). The thyroid diseases were based on clinical diagnosis in medical charts. Thus, the final study sample was 922 singleton newborns.

\section{Measurements of Cord Serum FT3, FT4, TSH, and TPOAb}

Immediately after delivery, cord blood sample was collected and put into serum separation tubes. The tubes were rested for $30 \mathrm{~min}$ at room temperature before centrifugation to allow coagulation. Aliquotes of serum samples were stored at $-80^{\circ} \mathrm{C}$ until assays.

Cord blood serum FT3, FT4, TSH, and TPOAb concentration were measured by chemiluminescent microparticle immunoassay using the Architect system (Abbott Laboratories, Abbott Park, IL, USA) in the clinical laboratory of the Shanghai International Peace Maternity and Child Health Hospital of Chinese Welfare Foundation; the lab is certified by the China National Accreditation Board. QA/QC procedures were performed for all analyses in accordance with the system's instructions. The inter- and intra assay coefficients of variation were 5.9 and $5.0-5.1 \%$ for FT3, 2.5-6.3 and 3.5\% for FT4, 2.5-4.1 and $2.2-2.9 \%$ for $\mathrm{TSH}$, respectively. The limits of detection (LOD) for FT3, FT4, TSH, and TPOAb were 1.54 $\mathrm{pmol} / \mathrm{L}, 5.15 \mathrm{pmol} / \mathrm{L}, 0.01 \mathrm{mIU} / \mathrm{L}$ and $0.5 \mathrm{IU} / \mathrm{mL}$, respectively. The cross-reactivity was $0.002 \%$ between T3 and T4 assays for FT4 > 1000,000 pg/mL, and $0.0035 \%$ for FT3 > 12,000 $\mathrm{ng} / \mathrm{dL}$. Therefore, the assays showed virtually no cross-reactivity between FT3 and FT4 in the present study. The detectable TPOAb was $\geq 0.5 \mathrm{IU} / \mathrm{mL}$. The TPOAb positive was defined as $\geq$ $5.61 \mathrm{IU} / \mathrm{mL}$.

\section{Maternal and Delivery Factors}

A face-to-face questionnaire interview was conducted at enrollment to collect data on maternal characteristics including age, weight before pregnancy, height, education, annual household income, parity, and smoking and passive smoking (husband smoking) during pregnancy (there were only 2 women who smoked in the cohort). Pregnancy complications and comorbidities, the use of artificial fertilization, mode of delivery [vaginal delivery, C-section (medical-indicated or on-request /non-medical-indicated)], type of labor (spontaneous or induced), duration of labor (the first and second stages) were abstracted from medical charts using a standardized data collection form.

The diagnoses of hyperthyroidism and hypothyroidism were made by the treating obstetrician based on the Chinese guidelines for the diagnosis and treatment of thyroid diseases in pregnancy 
(31). Preeclampsia was diagnosed by obstetricians (32). GDM was defined according to the International Association of Diabetes and Pregnancy Study Groups (IADPSG) criteria (33).

C-section deliveries were divided into two categories, medicalindicated and non-medical-indicated. Non-medical-indicated $\mathrm{C}$-section was defined as a $\mathrm{C}$-section on maternal request in the absence of medical indications, and medical-indicated C-section was defined as a C-section on maternal and/or fetal indications (34). The duration of first stage of labor was defined as the duration between the onset of regular painful uterus contractions and full dilatation of the cervix. The duration of second stage of labor was defined from complete cervical dilation to delivery of the neonate (35). Long duration of labor during the first or second stage was defined as $>75$ th percentile.

Advanced maternal age was defined as age $\geq 35$ years (25). Maternal age was categorized into 3 groups: $<30,30-34$ and $\geq 35$ years. Pre-pregnancy body mass index (BMI) was calculated as pre-pregnancy weight divided by the square of height $\left(\mathrm{kg} / \mathrm{m}^{2}\right)$, and categorized according to the World Health Organization (WHO) criteria: underweight, $<18.5 \mathrm{~kg} / \mathrm{m}^{2}$; normal weight, $18.5-24.9 \mathrm{~kg} / \mathrm{m}^{2}$; overweight and obesity, $\geq 25.0 \mathrm{~kg} / \mathrm{m}^{2}$ (36). Maternal education levels were grouped into two categories: high school or lower; college/university.

\section{Neonatal Factors}

Infant sex, 5-min Apgar score, gestational age (GA) at delivery and birth weight were obtained from medical charts.

GA at delivery was determined by the date of last menstrual period (LMP) or early fetal ultrasound dating ( $<20$ weeks). When the difference in GA estimates by the two methods was $\geq 2$ weeks, the ultrasound-based estimate was used. Birth weight was categorized as low (LBW, $<2,500 \mathrm{~g})$, normal $(2,500-$ $4,000 \mathrm{~g}$ ) and high (HBW, >4,000 g). Birth weight for GA was defined according to the Chinese references for male and female newborns separately (37), and classified as small for GA (SGA, <10th percentile), appropriate for GA (AGA, 10th-90th percentile), and large for GA (LGA, >90th percentile).

\section{Statistical Analyses}

Descriptive statistics (mean, SE, median, and selected percentiles) were presented for cord blood FT3, FT4, TSH, TPOAb, and FT3/FT4 ratio. We calculated FT3/FT4 ratio as FT3 divided by FT4, which is a proxy of deiodinase activity (38). The outcome variable was each of the cord blood thyroid parameters. Logistic regression was used for TPOAb detectability as the outcome variable, and linear regressions were used for cord blood FT3, FT4, TSH, and FT3/FT4 ratio as the outcome variables. To examine the association with maternal age, the models were adjusted for pre-pregnancy BMI $\left(<18.5,18.5-24.9, \geq 25.0 \mathrm{~kg} / \mathrm{m}^{2}\right)$, hypertensive disorders of pregnancy (chronic hypertension, gestational hypertension, preeclampsia, and none), GDM or pre-existed diabetes, infant sex and gestational age. To examine the associations with mode of delivery, induction of labor and duration of first or second stage of labor (among vaginal deliveries only), the models were additionally adjusted for maternal age $(<30,30-34$, and $\geq 35$ years), and parity. To examine the association with fetal growth, the models were adjusted for maternal age $(<30,30-34$, and $\geq 35$ years), pre-pregnancy BMI $\left(<18.5,18.5-24.9, \geq 25.0 \mathrm{~kg} / \mathrm{m}^{2}\right)$, hypertensive disorders of pregnancy, GDM or pre-existed diabetes, infant sex, and gestational age.

The primary association of interest is whether advanced maternal age is associated with cord blood thyroid parameters (FT3, FT4, TSH levels, FT3/FT4 ratio, and TPOAb). Two-sided $p<0.025$ were considered statistically significant. All analyses were performed using the SAS 9.2 software (SAS Institute, Inc, Cary, NC, USA).

\section{RESULTS}

\section{Study Population}

This study included 922 mothers without thyroid diseases and their newborns. The characteristics of the study cohort are shown in Table 1. There were $97.3 \%$ mothers of Han Chinese, $5.6 \%$ with age $\geq 35$ years, and $11.1 \%$ with overweight or obesity. The rates of gestational hypertension, preeclampsia and GDM were $3.7,2.4$, and $11.7 \%$, respectively. Rates of C-section and nonmedical-indicated C-section were 75.5 and $25.0 \%$, respectively. All newborns had normal 5-min Apgar score ( $\geq 8)$. The mean \pm SE of birth weight was $3,430 \pm 14 \mathrm{~g}$.

\section{FT3, FT4, FT3/FT4 Ratio, TSH, and TPOAb Concentrations in Cord Blood}

Cord serum FT3 and FT4 concentrations were 0.32 (95\%CI: $0.15,0.49) \mathrm{pmol} / \mathrm{L}$ and 0.19 (95\%CI: -0.06, 0.44) $\mathrm{pmol} / \mathrm{L}$ higher, and TSH concentration was 4.27 (95\%CI: 3.64, 4.90) $\mathrm{mIU} / \mathrm{L}$ lower in newborns born via $\mathrm{C}$-section than those born by vaginal deliveries (Table 2). Therefore, cord blood thyroid parameters were further described in C-section and vaginal deliveries separately (Table S1). The mean (SD) cord serum FT3, FT4, and TSH concentrations were 1.90 (1.16) pmol/L, 13.44 (1.66) $\mathrm{pmol} / \mathrm{L}$, and $5.15(2.60) \mathrm{mIU} / \mathrm{L}$ in newborns born via Csection, and $1.62(0.93) \mathrm{pmol} / \mathrm{L}, 13.17$ (1.44) $\mathrm{pmol} / \mathrm{L}$ and 9.27 (6.76) $\mathrm{mIU} / \mathrm{L}$ in newborns born via vaginal delivery. Mean (SD) of FT3/FT4 ratio was 0.17 (0.42) in C-section deliveries, and 0.12 (0.07) in vaginal deliveries (Table S1).

\section{Labor-Related Factors and Cord Blood Thyroid Parameters}

In vaginal deliveries, cord blood FT3 concentration was 0.28 (95\%CI: 0.01, 0.56) pmol/L lower, while TSH concentration was 2.85 (95\%CI: 0.97, 4.74) $\mathrm{mIU} / \mathrm{L}$ higher in newborns born by induction of labor than those by spontaneous labor (Table 2). Cord blood TSH was 2.41 (95\%CI: $0.18,4.65) \mathrm{mIU} / \mathrm{L}$ higher in newborns with long duration of second stage of labor $(>75$ th percentile) compared with other infants (Table 2).

\section{Maternal Age and Cord Blood Thyroid Parameters}

Advanced maternal age was associated with lower FT3 in C-section delivery (Table 3). Compared with that in newborns of mothers of age $<30$ years, cord serum FT3 concentration was 0.15 (95\%CI: $-0.03,0.33) \mathrm{pmol} / \mathrm{L}$ lower in newborns of mothers 
TABLE 1 | Characteristics of singleton term newborns $(n=922)$ of mothers with normal thyroid function in a Shanghai birth cohort, China.

\begin{tabular}{|c|c|}
\hline Characteristic & $\boldsymbol{N}(\%)$ or Mean $\pm \mathrm{S}$ \\
\hline Maternal age (years) & $29.15 \pm 0.11$ \\
\hline$<30$ & $558(60.6 \%)$ \\
\hline $30-34$ & $311(33.8 \%)$ \\
\hline$\geq 35$ & $52(5.6 \%)$ \\
\hline Prepregnancy BMI (kg/m²) & $21.24 \pm 0.10$ \\
\hline$<18.5$ & $150(16.3 \%)$ \\
\hline $18.5-24.9$ & $668(72.6 \%)$ \\
\hline$\geq 25$ & $102(11.1 \%)$ \\
\hline \multicolumn{2}{|l|}{ Maternal education } \\
\hline High school or lower & $125(13.6 \%)$ \\
\hline College/university & $796(86.4 \%)$ \\
\hline Passive smoking during pregnancy & $284(31.1 \%)$ \\
\hline \multicolumn{2}{|l|}{ Hypertension } \\
\hline Chronic hypertension & $7(0.8 \%)$ \\
\hline Gestational hypertension & $34(3.7 \%)$ \\
\hline Preeclampsia & $22(2.4 \%)$ \\
\hline Pre-existed diabetes & $3(0.3 \%)$ \\
\hline GDM & $108(11.7 \%)$ \\
\hline Parity $\geq 1$ & $90(9.8 \%)$ \\
\hline \multicolumn{2}{|l|}{ Mode of delivery } \\
\hline Vaginal & $226(24.5 \%)$ \\
\hline C-section (non-medical-indicated) & $230(25.0 \%)$ \\
\hline C-section (medical-indicated) & $465(50.5 \%)$ \\
\hline Infant sex (male) & 479 (52.0\%) \\
\hline GA (weeks) & $38.95 \pm 0.03$ \\
\hline Birth weight (g) & $3,430 \pm 14$ \\
\hline LBW & $8(0.9 \%)$ \\
\hline HBW & $82(8.9 \%)$ \\
\hline \multicolumn{2}{|l|}{ Birth weight for GA } \\
\hline SGA & $33(3.6 \%)$ \\
\hline LGA & 117 (12.7\%) \\
\hline FT3 (pmol/L) & $1.83 \pm 0.04$ \\
\hline FT4 (pmol/L) & $13.37 \pm 0.05$ \\
\hline FT3/ FT4 ratio & $0.16 \pm 0.01$ \\
\hline TSH (mIU/L) & $6.16 \pm 0.15$ \\
\hline $\mathrm{TPOAb} \geq 5.61 \mathrm{UU} / \mathrm{mL}$ & $85(9.3 \%)$ \\
\hline
\end{tabular}

Data presented are Mean \pm SE or $n(\%)$.

$B M I$, body mass index; GDM, gestational diabetes mellitus; C-section, cesarean section; GA, gestational age; LBW, low birth weight; HBW, high birth weight; SGA, small for gestational age; LGA, large for gestational age. FT3, free triiodothyronine; FT4, free thyroxine; TSH, thyroid-stimulating hormone.

aged 30-34 years, and 0.57 (95\%CI: $0.22,0.92) \mathrm{pmol} / \mathrm{L}$ lower in newborns of mothers of age $\geq 35$ years in C-section delivery. Similarly, the negative association between maternal age $(\geq 30$ years) and cord serum FT3 concentration was observed in vaginal deliveries $(p=0.07$, Table 3 ). Cord serum FT3/FT4 ratio was 0.02 (95\%CI: $0.0002,0.04$ ) lower in maternal age $\geq 30$ vs. $<30$ years in vaginal deliveries, and $0.09(95 \% \mathrm{CI}:-0.04,0.22)$ lower in maternal age $\geq 35$ vs. $<30$ years in C-section deliveries (Table 3 ). In sensitivity analysis, negative associations between advanced

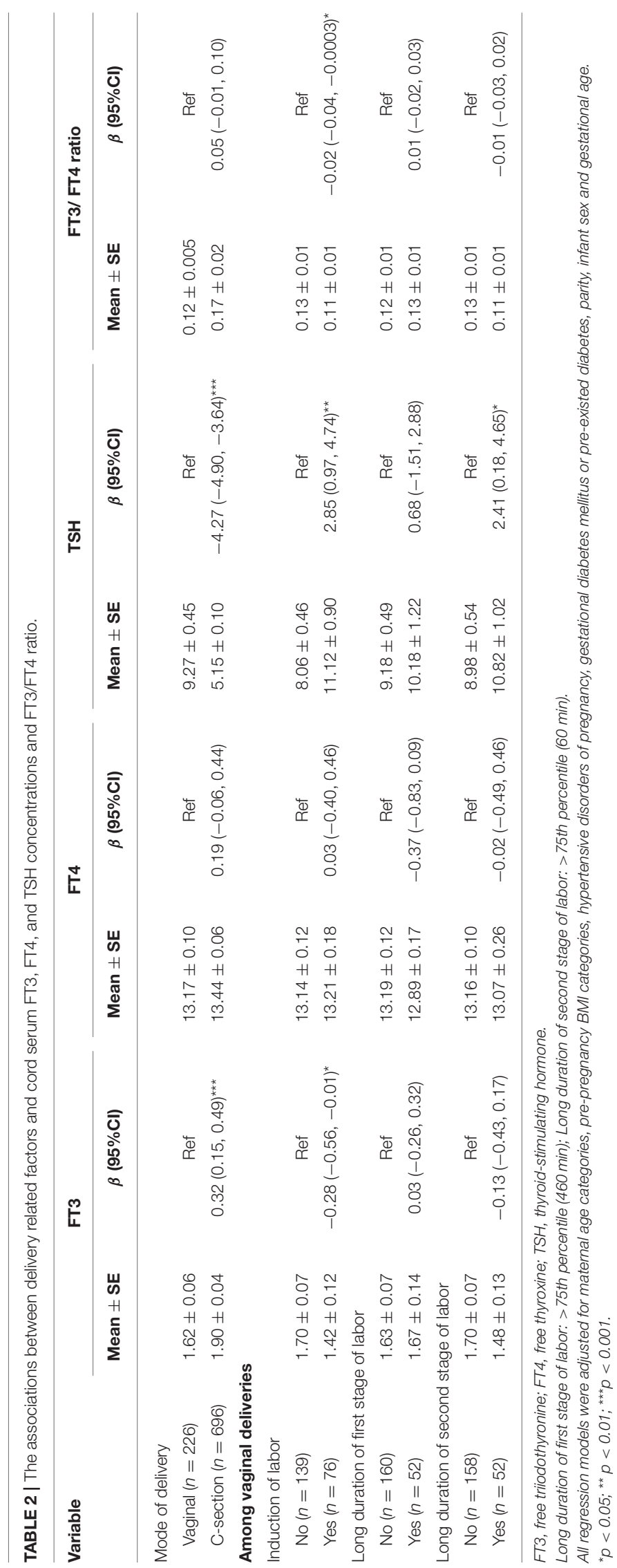




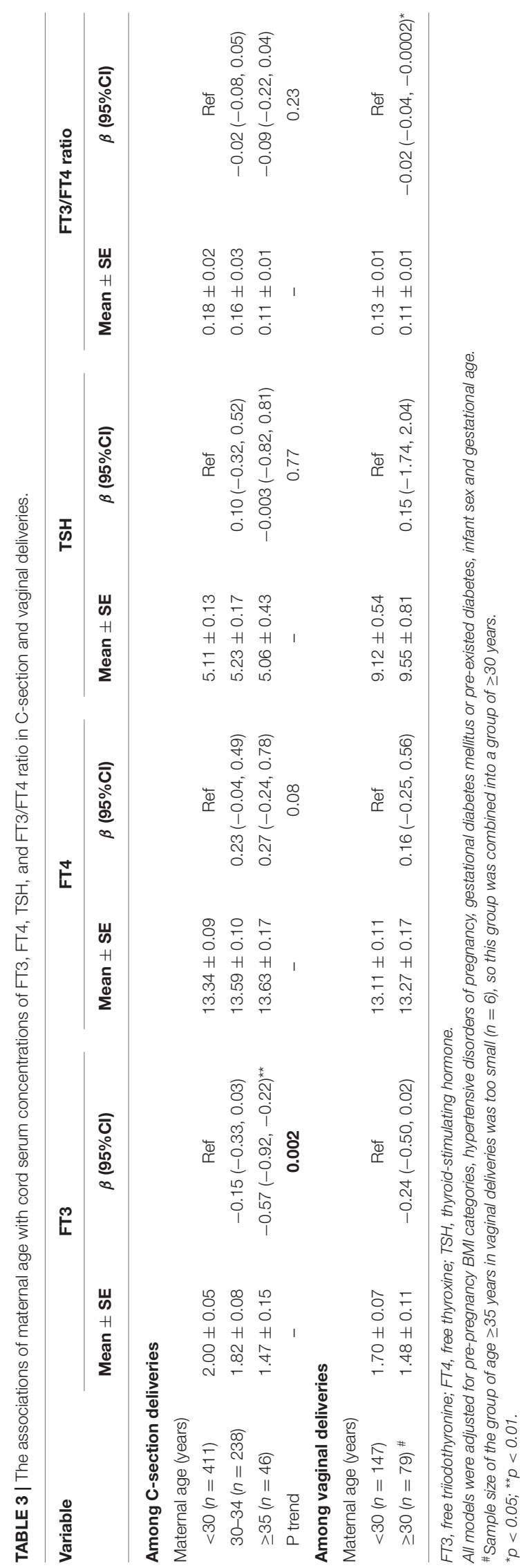

maternal age and FT3 were observed in non-medical-indicated C-section births ( $p=0.004$, Table S2).

Neither advanced maternal age nor mode of delivery was associated with the odds of cord serum TPOAb $\geq 5.61$ $\mathrm{IU} / \mathrm{mL}$ (Table S3).

\section{Fetal Growth and Cord Blood Thyroid Parameters}

In C-section deliveries, cord blood TSH concentration was 0.87 (95\%CI: $0.23,1.50) \mathrm{mIU} / \mathrm{L}$ higher in HBW vs. normal birth weight infants (Table 4). Similar association was observed between LGA and TSH ( $\beta=0.63,95 \%$ CI: $0.08,1.17)$. In vaginal deliveries, cord blood TSH concentration was 5.99 (95\%CI: 1.21, 10.77) $\mathrm{mIU} / \mathrm{L}$ higher in SGA vs. AGA infants (Table 4).

\section{Prenatal Factors and Cord Blood Thyroid Parameters}

There were no significant associations between GDM or hypertensive disorders of pregnancy and cord serum thyroid parameters (Table S4), except that chronic hypertension $(n=7)$ was associated with $2.35(95 \% \mathrm{CI}: 1.54,3.16) \mathrm{pmol} / \mathrm{L}$ higher cord serum FT3 concentration and 0.92 (95\%CI: 0.66, 1.19) higher FT3/FT4 ratio. TPOAb positive was not associated with FT3, FT4, TSH, or FT3/FT4 ratio.

We performed sensitivity analyses to compare the cord blood thyroid parameters in newborns of mothers without any thyroid diseases $(n=922)$ with those with hyperthyroidism $(n=$ $10)$ or hypothyroidism $(n=26)$, and observed no significant differences in cord blood serum FT3, FT4 and TSH levels among the three groups, but the rate of cord blood TPOAb positive ( $\geq 5.61 \mathrm{IU} / \mathrm{mL}$ ) was higher in hyperthyroidism (70.0\%) and hypothyroidism $(46.2 \%)$ vs. the normal $(9.3 \%)$ groups (Table S5). In this population, women with thyroid disorders receive treatment immediately after diagnosis.

\section{DISCUSSION}

We have presented the data on cord serum levels of FT3, FT4, FT3/FT4 ratio, TSH, and TPOAb in a contemporary Chinese term birth cohort. Our study is the first to show that advanced maternal age is associated with lower FT3 in cord blood.

A novel finding of our study was that advanced maternal age was associated with lower FT3 in cord blood. Neonatal thyroid hormone levels are sensitive to variations of maternal thyroid function and iodine status $(39,40)$. A study also showed that pregnant women of older age had lower FT3 and FT4 levels in the first trimester, and lower levels of FT4 in the second trimester (27). Advanced maternal age has been associated with higher risks of subclinical hypothyroidism (41) and neonatal CH (42) in some studies, but lack of association has also been reported in other studies $(43,44)$. While it is unclear why advanced maternal age may affect cord blood FT3 levels, we speculate that lower activity of deiodinase type 2 (D2) may be a contributing factor $(2,38)$. D2 is critical in transforming T4 to FT3 (2). FT3/FT4 ratio is an indicator of D2 activity in converting FT4 into FT3 (38). In addition, type 3 deiodinase (D3) may play a critical role 
TABLE 4 | The associations of fetal growth status with cord serum concentrations of FT3, FT4, TSH, and FT3/FT4 ratio in C-section and vaginal deliveries.

\begin{tabular}{|c|c|c|c|c|c|c|c|c|}
\hline \multirow[t]{2}{*}{ Variable } & \multicolumn{2}{|r|}{ FT3 } & \multicolumn{2}{|c|}{ FT4 } & \multicolumn{2}{|c|}{ TSH } & \multicolumn{2}{|c|}{ FT3/FT4 ratio } \\
\hline & Mean \pm SE & $\beta(95 \% \mathrm{Cl})$ & Mean \pm SE & $\beta(95 \% \mathrm{Cl})$ & Mean \pm SE & $\beta(95 \% \mathrm{Cl})$ & Mean \pm SE & $\beta(95 \% \mathrm{Cl})$ \\
\hline \multicolumn{9}{|l|}{ Among C-section deliveries } \\
\hline \multicolumn{9}{|l|}{ Birth weight $^{a}$} \\
\hline $\operatorname{LBW}(n=7)$ & $1.58 \pm 0.43$ & $0.02(-0.84,0.88)$ & $13.11 \pm 0.58$ & $-0.50(-1.77,0.77)$ & $5.23 \pm 0.40$ & $0.02(-1.98,2.03)$ & $0.12 \pm 0.03$ & $0.03(-0.28,0.35)$ \\
\hline Normal birthweight $(n=612)$ & $1.90 \pm 0.05$ & Ref & $13.44 \pm 0.06$ & Ref & $5.06 \pm 0.10$ & Ref & $0.17 \pm 0.02$ & Ref \\
\hline HBW $(n=77)$ & $1.93 \pm 0.09$ & $-0.03(-0.30,0.24)$ & $13.49 \pm 0.24$ & $0.08(-0.32,0.48)$ & $5.88 \pm 0.44$ & $0.87(0.23,1.50)^{\star \star}$ & $0.15 \pm 0.01$ & $-0.03(-0.13,0.07)$ \\
\hline \multicolumn{9}{|l|}{ Birth weight for $G A^{b}$} \\
\hline SGA $(n=25)$ & $2.02 \pm 0.20$ & $0.08(-0.37,0.54)$ & $13.13 \pm 0.24$ & $-0.28(-0.95,0.38)$ & $4.91 \pm 0.36$ & $-0.13(-1.18,0.92)$ & $0.16 \pm 0.01$ & $-0.04(-0.21,0.12)$ \\
\hline AGA $(n=563)$ & $1.89 \pm 0.05$ & Ref & $13.43 \pm 0.07$ & Ref & $5.06 \pm 0.10$ & Ref & $0.17 \pm 0.02$ & Ref \\
\hline $\operatorname{LGA}(n=108)$ & $1.95 \pm 0.08$ & $0.05(-0.19,0.29)$ & $13.59 \pm 0.18$ & $0.13(-0.21,0.47)$ & $5.70 \pm 0.33$ & $0.63(0.08,1.17)^{\star}$ & $0.15 \pm 0.01$ & $-0.03(-0.12,0.06)$ \\
\hline \multicolumn{9}{|l|}{ Among vaginal deliveries } \\
\hline \multicolumn{9}{|l|}{ Birth weighta ${ }^{a}$} \\
\hline $\operatorname{LBW}(n=1)$ & & - & & - & & - & & - \\
\hline Normal birthweight $(n=220)$ & $1.64 \pm 0.06$ & Ref & $13.17 \pm 0.10$ & Ref & $9.09 \pm 0.42$ & Ref & $0.12 \pm 0.005$ & Ref \\
\hline HBW $(n=5)$ & $1.30 \pm 0.55$ & $-0.28(-1.11,0.55)$ & $12.94 \pm 0.88$ & $-0.09(-1.38,1.20)$ & $9.83 \pm 4.63$ & $1.01(-4.67,6.70)$ & $0.10 \pm 0.04$ & $-0.02(-0.09,0.04)$ \\
\hline \multicolumn{9}{|l|}{ Birth weight for $G A^{b}$} \\
\hline $\operatorname{SGA}(n=8)$ & $0.99 \pm 0.38$ & $-0.75(-1.41,-0.09)^{\star}$ & $12.96 \pm 0.51$ & $-0.15(-1.18,0.88)$ & $14.66 \pm 5.12$ & $5.99(1.21,10.77)^{\star}$ & $0.08 \pm 0.03$ & $-0.06(-0.11,-0.01)^{*}$ \\
\hline AGA $(n=209)$ & $1.66 \pm 0.06$ & Ref & $13.15 \pm 0.09$ & Ref & $8.98 \pm 0.42$ & Ref & $0.13 \pm 0.005$ & Ref \\
\hline LGA $(n=9)$ & $1.34 \pm 0.35$ & $-0.28(-0.90,0.34)$ & $13.81 \pm 1.05$ & $0.68(-0.28,1.65)$ & $11.21 \pm 3.29$ & $2.30(-2.19,6.78)$ & $0.10 \pm 0.03$ & $-0.03(-0.08,0.02)$ \\
\hline
\end{tabular}

FT3, free triiodothyronine; FT4, free thyroxine; TSH, thyroid-stimulating hormone. LBW, low birth weight; HBW, high birth weight; SGA, small for gestational age; AGA, appropriate for gestational age; LGA, large for gestational age. ${ }^{a}$ Models were adjusted for maternal age categories, pre-pregnancy BMI categories, hypertensive disorders of pregnancy, gestational diabetes mellitus or pre-existed diabetes, infant sex and gestational age.

${ }^{b}$ Models were adjusted for maternal age categories, pre-pregnancy BMI categories, hypertensive disorders of pregnancy, gestational diabetes mellitus or pre-existed diabetes, and infant sex.

${ }^{*} p<0.05 ;{ }^{* *} p<0.01 ;-$ sample size too small to compute. 
in the decrease in FT3. D3 is upregulated in hypoxia, which is a potential consequence of labor-related adverse events (45). Advanced maternal age has been associated with an increased risk of intrapartum anoxia (46). Neonatal T4 and TSH levels may be associated with cognitive and verbal abilities in children (4, 9, 4749 ), and such associations were either positive or negative in previous studies (4, 9, 47-49). A study reported that maternal age $>30$ years was associated with lower IQ in the offspring (50). Importantly, our finding suggests that decreased neonatal thyroid hormones may be a potential mechanism in the adverse impact of advanced maternal age on neurodevelopment in the literature. We observed similar associations between maternal age and FT3 in cord blood in C-section and vaginal deliveries. In this study, 52 mothers were 35 years or older, and the sample size was relatively small. However, we did detect a significant effect of advanced maternal age ( $\geq 35$ years) on cord blood FT3 level.

Gestational age was positively associated with FT3 in cord blood in term infants in our study cohort. In human fetal blood samples (by cordocentesis or percutaneous umbilical cord blood sampling), fetal serum concentrations of FT3 increased from mid-gestation onwards, with an exponential rise closer to term (51), consisting with the progressive increases of fetal FT4 concentrations during pregnancy (2), as the fetal thyroid axis becomes mature during late gestation (1).

We found that high birth weight and LGA were associated with higher TSH. Previous studies have reported positive association (21), or no associations between birth weight and neonatal TSH levels $(23,24)$. The different findings may be partly due to the differences in ethnicity (8) and measurement method.

Our study confirmed the elevated cord blood TSH levels in newborns of vaginal vs. C-section deliveries (18), and with induction of labor or long duration of second stage of labor (7, $17,52)$. Our study also found that newborns born via C-section delivery had higher cord serum FT3 than those born via vaginal delivery. This might be due to the decreased levels of thyroid hormone distributer proteins (THDPs) which include albumin, transthyretin (TTR), and thyroxine-binding globulin (TBG) (53). As albumin, TTR and TBG are negative acute phase plasma proteins, all of them will be down-regulated in situations of stress or surgery (53), resulting in increased FT3. In addition, this can be, in part explained by the role of D3. Since D3 is upregulated in hypoxia, D3 level may rise during vaginal delivery (54), resulting in decrease in T3 and reduction in oxygen consumption (45). A cohort study reported that compared to spontaneous delivery, C-section delivery was associated with lower cord blood serum TSH and FT4 in newborns, but the association disappeared in childhood (around age 6 years) (23).

Cord blood TSH was positively correlated to heel prick blood TSH level (55), which is commonly used in neonatal thyroid function screening (10). The heel prick blood TSH level can be affected by the timing of sample collection and temperature $(6,12)$. Because newborns commonly experience a physiological surge in TSH levels starting around 30 min after birth until $72 \mathrm{~h}$ (56), TSH in heel-prick samples collected between half to $72 \mathrm{~h}$ after birth can be higher than cord blood TSH level.

In addition, thyroid hormone levels vary by assay methods with increasing automation, sensitivity and specificity from radioimmunoassay (RIA) to chemiluminescent immunoassay (CLIA) during the last two decades $(57,58)$. In comparison with other studies using CLIA method in China and in other countries, cord blood serum TSH levels in our study (medians $4.59 \mathrm{mIU} / \mathrm{L}$ in C-section delivery, and $7.27 \mathrm{mIU} / \mathrm{L}$ in vaginal delivery) was comparable to those reported in Tianjin (median $4.71 \mathrm{mIU} / \mathrm{L}, n=174$ ) (59), Taiwan (median $4.99 \mathrm{mIU} / \mathrm{L}, n=$ 107) (60), Shandong (median $8.84 \mathrm{mIU} / \mathrm{L}, n=107)(61)$ and Beijing (median $9.44 \mathrm{mIU} / \mathrm{L}, n=157)(62)$, as well as the values reported in Belgium (6.6 mIU/L, $n=198$, Direct CLIA) (63), but lower than those reported in Netherlands $(9.42 \mathrm{mIU} / \mathrm{L}, n=$ 2724, CLIA) (21) and Spain (mean $12.2 \mathrm{mIU} / \mathrm{L}, n=161$, CLIA) (40). Similarly, median cord blood FT3 was around $2 \mathrm{pmol} / \mathrm{L}$ and median cord blood FT4 level was $13-15 \mathrm{pmol} / \mathrm{L}$ in previous studies and this study (62-66).

We observed no significant association between the presence of TPOAb and FT3, FT4, TSH, or any observed perinatal factors. Neonatal TPOAb was transferred from the mother (67), and is considered normal when undetectable. Some studies linked the presence of TPOAb in cord blood to a higher risk for developing autoimmune thyroiditis in children and adolescents (5).

The study population had a high $\mathrm{C}$-section rate with a large proportion of on-request or non-medical-indicated C-sections. This offers a unique opportunity to assess the cord serum levels of thyroid hormone in physiological conditions. In addition, the relatively large sample size provides robust estimates of cord serum FT3, FT4, TSH, and TPOAb levels in a contemporary Chinese birth cohort. In China, salt iodine fortification is common. The proportion of urinary iodine concentration $<150$ $\mathrm{mg} / \mathrm{g}$ creatinine was $34-48 \%$ during pregnancy in a Shanghai study population (68). In this study, we excluded women with thyroid diseases before or during pregnancy.

Our study had limitations. This is an observational study, and cannot be used to establish causality. Of note, the assays of FT4 and FT3 can be interfered by thyroid binding protein levels.

\section{CONCLUSIONS}

We have presented the data on cord serum levels of thyroid hormones in a Chinese fullterm birth cohort. Our study showed for the first time that advanced maternal age was associated with lower cord blood FT3. Future research is needed to understand whether this association may mediate the association of advanced maternal age with impaired neurodevelopment in early life.

\section{DATA AVAILABILITY STATEMENT}

The datasets generated for this study are available on request to the corresponding author.

\section{ETHICS STATEMENT}

The study was reviewed and approved by Medical Ethics Committee of Xinhua Hospital, Shanghai Jiao Tong University School of Medicine. All participants provided their written informed consent to participate in this study. 


\section{AUTHOR CONTRIBUTIONS}

FO conceived and designed the study. FO, JZ, and $\mathrm{ZL}$ coordinated and conducted the data collection and measurements. FO and PF analyzed and interpreted data and drafted the manuscript. Z-CL, NT, WW, ZL, and JZ interpreted data and intensively revised the manuscript. All authors have approved the final version of the manuscript.

\section{FUNDING}

This study was supported by grants from the National Natural Science Foundation of China (NSFC, Nos. 81673178, 81961128023), the Ministry of Science and Technology of China (No. 2017YFE0124700), NSFC (No. 81372954), Shanghai Municipal Education Commission-Gaofeng Clinical

\section{REFERENCES}

1. Forhead AJ, Fowden AL. Thyroid hormones in fetal growth and prepartum maturation. J Endocrinol. (2014) 221:R87-103. doi: 10.1530/JOE14-0025

2. Patel J, Landers K, Li H, Mortimer RH, Richard K. Delivery of maternal thyroid hormones to the fetus. Trends Endocrinol Metab. (2011) 22:16470. doi: 10.1016/j.tem.2011.02.002

3. Takasu N, Yoshimura Noh J. Hashimoto's thyroiditis: TGAb, TPOAb, TRAb and recovery from hypothyroidism. Exp Rev Clin Immunol. (2008) 4:22137. doi: 10.1586/1744666X.4.2.221

4. Williams FL, Watson J, Ogston SA, Visser TJ, Hume R, Willatts P. Maternal and umbilical cord levels of T4, FT4, TSH, TPOAb, and TgAb in term infants and neurodevelopmental outcome at 5.5 years. J Clin Endocrinol Metab. (2013) 98:829-38. doi: 10.1210/jc.2012-3572

5. Svensson J, Lindberg B, Ericsson UB, Olofsson P, Jonsson B, Ivarsson SA. Thyroid autoantibodies in cord blood sera from children and adolescents with autoimmune thyroiditis. Thyroid. (2006) 16:79-83. doi: 10.1089/thy.2006.16.79

6. Clapin H, Lewis BD, Greed L, Dawkins H, O'Leary P. Factors influencing neonatal thyroid-stimulating hormone concentrations as a measure of population iodine status. J Pediatr Endocrinol Metab. (2014) 27:1016. doi: 10.1515/jpem-2013-0189

7. Chan LY, Leung TN, Lau TK. Influences of perinatal factors on cord blood thyroid-stimulating hormone level. Acta Obstet Gynecol Scand. (2001) 80:1014-8. doi: 10.1034/j.1600-0412.2001.801108.x

8. Herbstman J, Apelberg BJ, Witter FR, Panny S, Goldman LR. Maternal, infant, and delivery factors associated with neonatal thyroid hormone status. Thyroid. (2008) 18:67-76. doi: 10.1089/thy.2007.0180

9. Oken E, Braverman LE, Platek D, Mitchell ML, Lee SL, Pearce EN. Neonatal thyroxine, maternal thyroid function, and child cognition. J Clin Endocrinol Metab. (2009) 94:497-503. doi: 10.1210/jc.2008-0936

10. Ford G, LaFranchi SH. Screening for congenital hypothyroidism: a worldwide view of strategies. Best Pract Res Clin Endocrinol Metab. (2014) 28:17587. doi: 10.1016/j.beem.2013.05.008

11. Desai MP, Sharma R, Riaz I, Sudhanshu S, Parikh R, Bhatia V. Newborn screening guidelines for congenital hypothyroidism in india: recommendations of the Indian Society for Pediatric and Adolescent Endocrinology (ISPAE) - Part I: Screening and Confirmation of Diagnosis. Indian J Pediatr. (2018) 85:440-7. doi: 10.1007/s12098-0172575-y

12. Ryckman KK, Berberich SL, Shchelochkov OA, Cook DE, Murray JC. Clinical and environmental influences on metabolic biomarkers collected for newborn screening. Clin Biochem. (2013) 46:133-8. doi: 10.1016/j.clinbiochem.2012.09.013
Research Grant (No. 20152518), Gates Foundation HBGDki Project (No. OPP1153191), the National Human Genetic Resources Sharing Service Platform (No. 2005DKA21300), and the National Key Research and Development Program of China 2016YFC1000203.

\section{ACKNOWLEDGMENTS}

We thank Dr. Hongli Shi for her insightful comments on the manuscript.

\section{SUPPLEMENTARY MATERIAL}

The Supplementary Material for this article can be found online at: https://www.frontiersin.org/articles/10.3389/fendo. 2019.00913/full\#supplementary-material

13. Medici M, de Rijke YB, Peeters RP, Visser W, de Muinck Keizer-Schrama SM, Jaddoe VV, et al. Maternal early pregnancy and newborn thyroid hormone parameters: the Generation R study. J Clin Endocrinol Metab. (2012) 97:64652. doi: 10.1210/jc.2011-2398

14. Mehari A, Challa F, Gebreyesus G, Alemayehu D, Seifu D. Establishment of reference intervals of thyroid function tests from cord blood of neonates in two selected hospitals, Addis Ababa, Ethiopia. BMC Pediatr. (2016) 16:118. doi: 10.1186/s12887-016-0654-2

15. Yarhere IE, Jaja T, Oduwole A, Ibekwe MU, Suwaid S, Alkali Y, et al. Normative thyroid-stimulating hormone values for healthy nigerian newborns. Horm Res Paediatr. (2016) 85:22-8. doi: 10.1159/000441722

16. Manglik AK, Chatterjee N, Ghosh G. Umbilical cord blood TSH levels in term neonates: a screening tool for congenital hypothyroidism. Indian Pediatr. (2005) 42:1029-32.

17. Ryckman KK, Spracklen CN, Dagle JM, Murray JC. Maternal factors and complications of preterm birth associated with neonatal thyroid stimulating hormone. J Pediatr Endocrinol Metab. (2014) 27:929-38. doi: 10.1515/jpem-2013-0366

18. Gupta A, Srivastava S, Bhatnagar A. Cord blood thyroid stimulating hormone level-interpretation in light of perinatal factors. Indian Pediatr. (2014) 51:326. doi: 10.1007/s13312-014-0330-2

19. Trumpff C, Vandevijvere S, Moreno-Reyes R, Vanderpas J, Tafforeau J, Van Oyen $\mathrm{H}$, et al. Neonatal thyroid-stimulating hormone level is influenced by neonatal, maternal, and pregnancy factors. Nutr Res. (2015) 35:97581. doi: 10.1016/j.nutres.2015.09.002

20. Chan LY.-S., Chiu PY, Lau TK. Cord blood thyroid-stimulating hormone level in high-risk pregnancies. Eur J Obstetr Gynecol Reprod Biol. (2003) 108:142-5. doi: 10.1016/S0301-2115(02)00418-9

21. Medici M, Timmermans S, Visser W, de Muinck Keizer-Schrama SM. Jaddoe VW, Hofman A, et al. Maternal thyroid hormone parameters during early pregnancy and birth weight: the generation R study. J Clin Endocrinol Metab. (2013) 98:59-66. doi: 10.1210/jc.2012-2420

22. Rashmi, Seth A, Sekhri T, Agarwal A. Effect of perinatal factors on cord blood thyroid stimulating hormone levels. J Pediatr Endocrinol Metab. (2007) 20:59-64. doi: 10.1515/JPEM.2007.20.1.59

23. Korevaar TI, Chaker L, Jaddoe VW, Visser TJ, Medici M, Peeters RP. Maternal and birth characteristics are determinants of offspring thyroid function. J Clin Endocrinol Metab. (2016) 101:206-13. doi: 10.1210/jc.20153559

24. Shields BM, Knight BA, Hill A, Hattersley AT, Vaidya B. Fetal thyroid hormone level at birth is associated with fetal growth. J Clin Endocrinol Metab. (2011) 96:E934-8. doi: 10.1210/jc.2010-2814

25. Laopaiboon M, Lumbiganon P, Intarut N, Mori R, Ganchimeg T, Vogel J, et al. Advanced maternal age and pregnancy outcomes: a multicountry assessment. BJOG. (2014) 49-56. doi: 10.1111/1471-0528.12659 
26. Obstetrics Subgroup, Chinese Society of Obstetrics and Gynecology, Chinese Medical Association. [Guideline of preconception and prenatal care(2018)]. Chin J Obstet Gynecol. (2018) 53:713. doi: 10.3760/cma.j.issn.0529-567X.2018.01.003

27. Yu Y, Li X, Jiang S, Jiang W, Wu J, Wang Z, et al. Serum thyroid hormone levels among Chinese pregnant women. Gynecol Endocrinol. (2017) 33:7748. doi: $10.1080 / 09513590.2017 .1320375$

28. Liping Z, Min Q, Jing T, Liping H, Li D, Zhewei W, et al. Analysis on the condition of cesarean section in Shanghai. Maternal Child Health Care China. (2011) 26:4716-9.

29. Souza JP, Gulmezoglu A, Lumbiganon P, Laopaiboon M, Carroli G, Fawole $\mathrm{B}$, et al. Caesarean section without medical indications is associated with an increased risk of adverse short-term maternal outcomes: the 2004-2008 WHO Global Survey on Maternal and Perinatal Health. BMC Med. (2010) 8:71. doi: 10.1186/1741-7015-8-71

30. Ouyang F, Tang N, Zhang HJ, Wang X, Zhao S, Wang W, et al. Maternal urinary triclosan level, gestational diabetes mellitus and birth weight in Chinese women. Sci Total Environ. (2018) 626:451-7. doi: 10.1016/j.scitotenv.2018.01.102

31. Chinese Society of Endocrinology, Chinese Society of Perinatal Medicine. A guideline for diagnosis and management of thyroid diseases during pregnancy and postpartum. Chin J Perinatal Med. (2012) 15:385-403. doi: 10.3760/cma.j.issn.1007-9408.2012.07.001

32. Uzan J, Carbonnel M, Piconne O, Asmar R, Ayoubi JM. Pre-eclampsia: pathophysiology, diagnosis, and management. Vasc Health Risk Manag. (2011) 7:467-74. doi: 10.2147/VHRM.S20181

33. International Association of Diabetes, Pregnancy Study Groups Consensus Panel, Metzger BE, Gabbe SG, Persson B, Buchanan TA. International association of diabetes and pregnancy study groups recommendations on the diagnosis and classification of hyperglycemia in pregnancy. Diabetes Care. (2010) 33:676-82. doi: 10.2337/dc09-1848

34. Liu Y, Wang X, Zou L, Ruan Y, Zhang W. An analysis of variations of indications and maternal-fetal prognosis for caesarean section in a tertiary hospital of Beijing: A population-based retrospective cohort study. Medicine. (2017) 96:e5509. doi: 10.1097/MD.0000000000005509

35. Quinones JN, Gomez D, Hoffman MK, Ananth CV, Smulian JC, Skupski DW, et al. Length of the second stage of labor and preterm delivery risk in the subsequent pregnancy. Am J Obstet Gynecol. (2018) 219:467 e18. doi: 10.1016/j.ajog.2018.08.031

36. Obesity: preventing and managing the global epidemic. Report of a WHO consultation. World Health Organ Tech Rep Ser. (2000) 894:i-xii, 1-253.

37. Li Z, Rong Z, Shulian Z, Wenjing S, Weili Y, Xiaoli W, et al. Chinese neonatal birth weight curve for different gestational age. Chin J Pediatr. (2015) 53:97-103. doi: 10.3760/cma.j.issn.0578-1310.2015.02.007

38. Bassols J, Prats-Puig A, Soriano-Rodriguez P, Garcia-Gonzalez MM, Reid J, Martinez-Pascual M, et al. Lower free thyroxin associates with a less favorable metabolic phenotype in healthy pregnant women. J Clin Endocrinol Metab. (2011). 96:3717-23. doi: 10.1210/jc.2011-1784

39. Zimmermann MB, Aeberli I, Torresani T, Burgi H. Increasing the iodine concentration in the Swiss iodized salt program markedly improved iodine status in pregnant women and children: a 5-y prospective national study. Am J Clin Nutr. (2005) 82:388-92. doi: 10.1093/ajcn/82.2.388

40. Velasco I, Martin J, Gallego M, Gutierrez-Repiso C, Santiago P, Lopez-Siguero J. P, et al. Maternal-fetal thyroid function at the time of birth and its relation with iodine intake. Thyroid. (2013) 23:1619-26. doi: 10.1089/thy.2013.0035

41. Wang W, Yu X. Correlation analysis of hypothyroidism at first and second trimester with age factor. Chin J Woman Child Health Res. (2015) 3:499-500. doi: 10.3969/j.issn.1673-5293.2015.03.034

42. Rezaeian S, Poorolajal J, Moghimbegi A, Esmailnasab N. Risk factors of congenital hypothyroidism using propensity score: a matched case-control study. J Res Health Sci. (2013) 13:151-6.

43. Dieguez M, Herrero A, Avello N, Suarez P, Delgado E, Menendez E. Prevalence of thyroid dysfunction in women in early pregnancy: does it increase with maternal age? Clin Endocrinol. (2016) 84:121-6. doi: 10.1111/cen.12693

44. Medda E, Olivieri A, Stazi M, Grandolfo M, Fazzini C, Baserga $\mathrm{M}$, et al. Risk factors for congenital hypothyroidism: results of a population case-control study (1997-2003). Eur J Endocrinol. (2005) 153:765-73. doi: 10.1530/eje.1.02048

45. Diano S, Horvath T. Type 3 deiodinase in hypoxia: to cool or to kill? Cell Metab. (2008) 7:363-4. doi: 10.1016/j.cmet.2008.04.008
46. Pasupathy D, Wood AM, Pell JP, Fleming M, Smith GC. Advanced maternal age and the risk of perinatal death due to intrapartum anoxia at term. $J$ Epidemiol Commun Health. (2011) 65:241-5. doi: 10.1136/jech.2009.097170

47. Delahunty C, Falconer S, Hume R, Jackson L, Midgley P, Mirfield $\mathrm{M}$, et al. Levels of neonatal thyroid hormone in preterm infants and neurodevelopmental outcome at $51 / 2$ years: millennium cohort study. J Clin Endocrinol Metab. (2010) 95:4898-908. doi: 10.1210/jc.2010-0743

48. Freire C, Ramos R, Amaya E, Fernandez MF, Santiago-Fernandez P, LopezEspinosa M. J, et al. Newborn TSH concentration and its association with cognitive development in healthy boys. Eur J Endocrinol. (2010) 163:9019. doi: 10.1530/EJE-10-0495

49. Trumpff C, De Schepper J, Vanderfaeillie J, Vercruysse N, Van Oyen H, Moreno-Reyes R, et al. Thyroid-Stimulating Hormone (TSH) Concentration at Birth in Belgian Neonates and cognitive development at preschool age. Nutrients. (2015) 7:9018-32. doi: 10.3390/nu7115450

50. Myrskyla M, Silventoinen K, Tynelius P, Rasmussen F. Is later better or worse? Association of advanced parental age with offspring cognitive ability among half a million young Swedish men. Am J Epidemiol. (2013) 177:64955. doi: 10.1093/aje/kws237

51. Thorpe-Beeston JG, Nicolaides KH, Felton CV, Butler J, McGregor AM. Maturation of the secretion of thyroid hormone and thyroidstimulating hormone in the fetus. N Engl J Med. (1991) 324:5326. doi: 10.1056/NEJM199102213240805

52. Miyamoto N, Tsuji M, Imataki T, Nagamachi N, Hirose S, Hamada Y. Influence of mode of delivery on fetal pituitary-thyroid axis. Acta Paediatr Jpn. (1991) 33:363-8. doi: 10.1111/j.1442-200X.1991.tb01567.x

53. Rabah SA, Gowan IL, Pagnin M, Osman N, Richardson SJ. Thyroid hormone distributor proteins during development in vertebrates. Front Endocrinol. (2019) 10:506. doi: 10.3389/fendo.2019.00506

54. Mahato S, Chaudhary N, Lama S, Agarwal K, Bhatia B. Relationship of oxygen saturation with neonatal and maternal factors in vaginal and cesarean deliveries. J Nepal Med Assoc. (2015) 53:184-7. doi: 10.31729/jnma.2788

55. Guoqing W, Yada M, Xiaozhong L, Derong Q. Association between cord blood and heel blood TSH levels. Modern Prevent Med. (2004) 31:64. doi: 10.3969/j.issn.1003-8507.2004.01.027

56. Fisher DA, Klein AH. Thyroid development and disorders of thyroid function in the newborn. $N$ Engl J Med. (1981) 304:702-12. doi: 10.1056/NEJM198103193041205

57. Zhenjiang $\mathrm{H}$, Fengling W. Progress in detection of immunological methods thyroid hormone. Med Recapitulate. (2016) 22:332-4. doi: 10.3969/j.issn.1006-2084.2016.02.035

58. Wang $\mathrm{T}, \mathrm{Lu} \mathrm{H}$. Current status and advances in thyroid stimulating hormone assays. Med Recapitulate. (2016) 22:4895-8. doi: 10.3969/j.issn.1006-2084.2016.24.029

59. Chen W, Sang Z, Tan L, Zhang S, Dong F, Chu Z, et al. Neonatal thyroid function born to mothers living with long-term excessive iodine intake from drinking water. Clin Endocrinol. (2015) 83:399-404. doi: 10.1111/cen.12625

60. Shy CG, Huang HL, Chao HR, Chang-Chien GP. Cord blood levels of thyroid hormones and IGF-1 weakly correlate with breast milk levels of PBDEs in Taiwan. Int J Hyg Environ Health. (2012) 215:34551. doi: 10.1016/j.ijheh.2011.10.004

61. Ding G, Yu J, Chen L, Wang C, Zhou Y, Hu Y, et al. Polybrominated diphenyl ethers (PBDEs) and thyroid hormones in cord blood. Environ Pollut. (2017) 229:489-95. doi: 10.1016/j.envpol.2017.05.065

62. Yang L, Li J, Lai J, Luan H, Cai Z, Wang Y, et al. Placental Transfer of Perfluoroalkyl Substances and Associations with Thyroid Hormones: Beijing Prenatal Exposure Study. Sci Rep. (2016) 6:21699. doi: 10.1038/ srep21699

63. Maervoet J, Vermeir G, Covaci A, Van Larebeke N, Koppen G, Schoeters $\mathrm{G}$, et al. Association of thyroid hormone concentrations with levels of organochlorine compounds in cord blood of neonates. Environ Health Perspect. (2007) 115:1780-6. doi: 10.1289/ehp.10486

64. Lin SM, Chen FA, Huang YF, Hsing LL, Chen LL, Wu L. S, et al. Negative associations between PBDE levels and thyroid hormones in cord blood. Int $J$ Hyg Environ Health. (2011) 214:115-20. doi: 10.1016/j.ijheh.2010.10.002

65. Wilhelm M, Wittsiepe J, Lemm F, Ranft U, Krämer U, Fürst P, et al. The Duisburg birth cohort study: influence of the prenatal exposure to $\mathrm{PCDD} / \mathrm{Fs}$ and dioxin-like PCBs on thyroid hormone status in newborns and neurodevelopment of infants until the age of 24 months. Mutation Res. (2008) 659:83-92. doi: 10.1016/j.mrrev.2007.11.002 
66. Brucker-Davis F, Ferrari P, Boda-Buccino M, Wagner-Mahler K, Pacini P, Gal J, et al. Cord blood thyroid tests in boys born with and without cryptorchidism: correlations with birth parameters and in utero xenobiotics exposure. Thyroid. (2011) 21:1133-41. doi: 10.1089/thy.2010.0459

67. Alexander EK, Pearce EN, Brent GA, Brown RS, Chen H, Dosiou C, et al. Guidelines of the American Thyroid Association for the Diagnosis and Management of Thyroid Disease During Pregnancy and the Postpartum. Thyroid. (2017) 27:315-89. doi: 10.1089/thy.2016.0457

68. Wei Z, Wang W, Zhang J, Zhang X, Jin L, Yu X. Urinary iodine level and its determinants in pregnant women of Shanghai, China. Br J Nutr. (2015) 113:1427-32. doi: 10.1017/S0007114515000665
Conflict of Interest: The authors declare that the research was conducted in the absence of any commercial or financial relationships that could be construed as a potential conflict of interest.

Copyright (c) 2020 Fan, Luo, Tang, Wang, Liu, Zhang and Ouyang. This is an openaccess article distributed under the terms of the Creative Commons Attribution License (CC BY). The use, distribution or reproduction in other forums is permitted, provided the original author(s) and the copyright owner(s) are credited and that the original publication in this journal is cited, in accordance with accepted academic practice. No use, distribution or reproduction is permitted which does not comply with these terms. 